\title{
Triangulando visões sobre os valores organizacionais de empresas de software: um estudo de caso em uma universidade pública brasileira
}

\author{
Robilene C. Marques, Odette M. Passos, Fabiane A. S. Clemente \\ Instituto de Ciências Exatas e Tecnologia - Universidade Federal do Amazonas \\ Rua Nossa Senhora do Rosário, 3863 - 69100-000 - Tiradentes - AM - Brasil \\ \{robilenemarques@gmail.com, odette@ufam.edu.br, fabianecl@uol.com.br\}
}

\begin{abstract}
The market of you demands from the professionals not only competences, abilities, but that also know to adapt the personal values to the of the organization. Like this, the values can influence the decisions taken inside of an organization and consequently to determine his/her success or failure, being a factor that can be worked from the phase of the information technology professional's formation. For this reason, the objective of this work consisted of the analysis of the perception of the academic community of the courses of Systems of Information and Software engineering on 40 organizational values considered important in the software companies. The methodological procedures included methods quantitative and qualitative of research, besides documental analysis in the pedagogic political project of both courses, appropriating of statistical analysis and of content. As obtained result was possible to observe that as much the students as the teachers they recognize firstly that the organizational values, in the context of developers, are the most perceptible. In against departure, starting from a triangulation, the organizational values, in the context of high management, it was what more happened in the three visions in that the research was applied.
\end{abstract}

Resumo. O mercado de TI exige dos profissionais não somente competências, habilidades, mas que também saibam adequar os valores pessoais aos da organização. Assim, os valores podem influenciar as decisões tomadas dentro de uma organização e consequentemente determinar seu sucesso ou fracasso, sendo um fator que pode ser trabalhado desde a fase de formação do profissional de tecnologia da informação. Por este motivo, o objetivo deste trabalho consistiu na análise da percepção da comunidade acadêmica dos cursos de Sistemas de Informação e Engenharia de Software sobre 40 valores organizacionais considerados importantes nas empresas de software. Os procedimentos metodológicos incluíram métodos quantitativo e qualitativo de pesquisa, além de análise documental no projeto político pedagógico de ambos os cursos, apropriando-se de análise estatística e de conteúdo. Como resultado obtido foi possivel observar que tanto os discentes quanto os docentes reconhecem primeiramente que os valores organizacionais, no contexto de desenvolvedores, são o mais perceptível. Em contra partida, a partir de uma triangulação, os valores organizacionais, no contexto de alta gerência, foi o que mais incidiu nas três visões em que a pesquisa foi aplicada.

MARQUES, R. C.; PASSOS, O. M.; CLEMENTE, F. A. S.

Triangulando visões sobre os valores organizacionais de empresas de software: um estudo de caso em uma universidade pública brasileira

isys | Revista Brasileira de Sistemas de Informação, Rio de Janeiro, vol. 10, No. 2, pp. 111-137, 2017 


\section{Introdução}

A área de Tecnologia da Informação (TI) permanece em constante mudanças na busca da satisfação de seus clientes por meio de seus produtos e serviços diversificados [Gaspar et al. 2016]. Essas mudanças levam a um cenário competitivo das empresas de TI, que visam o sucesso por meio de inovação organizacional e tecnológica, porém esse processo exige um gerenciamento de difícil manutenção que pode sofrer com dificuldades por falta de mão de obra qualificada, incentivos, recursos, entre outros [Denizot 2014].

Por esse motivo as empresas de TI criam um cenário no qual se faz necessário um profissional que tenha um olhar voltado tanto para a gestão quanto para os aspectos tecnológicos, alinhando os planejamentos de TI ao planejamento estratégico da empresa [Correia 2013]. No entanto, a demanda por este tipo de funcionário tem sido preocupante, já que pode ter um alto custo para contratação e capacitação, tendo em vista que o mercado não deixa de exigir elevada capacidade técnica, flexibilidade e mobilidade [Mangia 2013].

A área de TI não costuma valorizar aspectos comportamentais, tais como crenças e valores para o processo de tomada decisão, porém esses aspectos são essenciais para uma organização, uma vez que caracteriza e norteia as atividades de uma empresa [Macedo e Barbosa 2013]. Em razão da percepção que os funcionários têm dos valores organizacionais (VOs) que determina o comportamento e possivelmente $\mathrm{o}$ comprometimento, estes são de interesse individual, coletivo e misto [Tamayo et al. 2000].

Todos estes aspectos permitem fazer um elo entre Instituição de Ensino Superior (IES) e o mercado de trabalho, pois muitos dos problemas encontrados neste setor podem começar a serem resolvidos no processo de formação do futuro profissional, adequando as práticas e aprendizado às necessidades do mercado [Hinterholz Junior et al. 2013]. Desse modo, torna-se importante que os profissionais de TI tenham conhecimento, não somente da área tecnológica, mas também da cultura organizacional (CO), em particular dos VOS que permeiam e orientam o funcionamento da empresa [Castro e Sá 2002].

Uma questão relevante diante do exposto, consiste na investigação da percepção de atores envolvidos no processo, quanto aos valores organizacionais nos cursos de Sistemas de Informação e Engenharia de Software. Isso se faz, em virtude da importância de analisar se tais valores são convergentes com a perspectiva do mercado de TI. A partir disso surge o problema da pesquisa que consiste em uma pergunta central: Os valores organizacionais considerados importantes para as empresas de software estão sendo percebidos pelos docentes e discentes da área de TI da Instituição estudada?

Neste contexto, a pesquisa teve como objetivo verificar se os VOs tidos como importantes para uma empresa de TI, são percebidos pelos docentes e discentes dos cursos de Sistemas de Informação (SI) e Engenharia de Software (ES) de uma universidade pública brasileira e descritos no projeto político pedagógico (PPP) desses dois cursos. 
A metodologia para se alcançar os objetivos consistiu em um estudo de caso como estratégia de pesquisa que se enquadra como quantitativa/qualitativa, por utilizar como instrumento, para a percepção dos discentes e docentes, um questionário e entrevistas, explorando a interpretação dos fenômenos ocorridos e qualitativa para analisar o PPP dos dois cursos. Para a análise dos dados obtidos foi utilizado análise estatística descritiva e de conteúdo, além de uma triangulação de perspectivas.

Os resultados obtidos permitiram inferir sobre a necessidade cada vez mais latente de se ter profissionais mais qualificados e condizentes com as demandas do mercado de trabalho, visto que a pesquisa tem um olhar para a formação do discente com o objetivo de atender as reais demandas do mercado de TI, tendo em vista que um dos principais diferenciais de desenvolvimento deste setor é o capital humano que contribui de maneira significativa e relevante como ferramenta de apoio as estratégias e negócios para as melhorias e soluções deste mercado [Brasscom 2015].

Esta pesquisa se distingue de outros trabalhos por possuir um foco mais voltado para os futuros profissionais em nível de formação e quais valores estão sendo percebidos dentro desse processo na percepção dos principais atores. Além disso, tratase de uma pesquisa que relaciona o processo de formação deste profissional com as demandas latentes no mercado de trabalho de TI.

\section{Fundamentação teórica}

\subsection{Cultura e valores organizacionais}

A concepção de Cultura Organizacional (CO) surgiu com a institucionalização (assume vida própria) nas organizações, ainda que inicialmente fosse tida apenas como uma variável que afetava as atitudes e comportamentos dos funcionários. Posteriormente, essa ideia foi trabalhada até o que conhecemos hoje como CO. As organizações que existiam antes dessa concepção, possuíam uma visão racional de coordenar e controlar seus colaboradores, porém ao perceber o impacto que a cultura exerce nos funcionários de uma organização, o olhar dos estudiosos voltou-se para essa nova forma de enxergar o contexto organizacional [Robbins 2005].

Os precursores no estudo acerca de CO surgiram a partir da década de 1950, quando Tavistock Jaques publicou um estudo sobre a influência de fatores sociais na produtividade de indivíduos [Peixoto e Mota 2012]. Em 1960, Mayo realizou uma experiência sobre a influência que as normas sociais e expectativas grupais exercem sobre o nível de produção. Já em 1979, Andrew Pettigrew associou a CO a significados que representam a realidade pessoal.

Na década de 1980, surgiu um dos principais autores de CO, Geert Hofstede que realizou uma pesquisa entre as décadas de 1960 e 70 em 50 países e 3 regiões continentais (África Ocidental, África Oriental e países da língua árabe) que serviu como base para diversas outras pesquisas. O estudo mostrou como resultado, significativas diferenças no comportamento e atitudes de funcionários além de constatar a influência da cultura nacional nos valores e atitudes nas atividades exercidas nas organizações [Machado et al. 2009].

Por consequência, o conceito de $\mathrm{CO}$ ganhou diversas definições sob o enfoque organizacional [Fernandes 2010]. Schein (1985) definiu a CO como "um conjunto de premissas que um grupo aprendeu a aceitar como resultado da solução de problemas de 
adaptação ao ambiente e de integração interna". As premissas vão além do que é observável e, os atos de sentir e pensar (atos inconscientes) dos membros de um grupo também são considerados [Tavares 1996].

Para Oliveira (1988) CO é um "conjunto de valores e crenças vigentes na organização e aos comportamentos individuais e coletivos decorrentes". Estes, uma vez definidas na empresa não se pode mudar drasticamente de uma hora para outra, pois tais mudanças afetam o cerne organizacional [Tavares 1996].

A CO contém basicamente sete características que a exprimem fundamentalmente em um ambiente organizacional: i) inovação e assunção de riscos: o grau em que os membros da organização estão dispostos a inovar e assumir riscos; ii) atenção aos detalhes: o grau em que se faz uma análise do comprometimento dos colaboradores com relação a precisão e atenção aos detalhes; iii) orientação para os resultados: o grau em que os meios para se chegar aos resultados são menos evidenciados do que os resultados; iv) orientação para as pessoas: o grau em que as decisões dos dirigentes são influenciadas pelos efeitos causados em cada indivíduo na organização; v) orientação para a equipe: o grau em que a ênfase é maior no coletivo do que no individual; vi) agressividade: o grau em que a competitividade predomina sobre os membros da organização; vi) estabilidade: o grau em que há uma preocupação com a manutenção da atual situação em contraste com o crescimento [Robbins 2005].

Existem, portanto, elementos mais difíceis de serem alterados e que são caracterizados por Schein (1992) em três níveis: i) artefatos, que são as estruturas e processos organizacionais visíveis; ii) valores, que trata-se de estratégias, objetivos e as filosofias; e iii) pressupostos que contemplam as crenças, percepções e pensamentos.

Ao analisar as características definidas por Robbins (2005) e a cultura de empresas de sucesso, é possível observar que os valores fazem parte dos fatores que influenciam os bons resultados alcançados por uma organização [Hofstede 1990]. Nesse sentido, Silva (2008) destaca que estes VOs motivam os colaboradores a se sentirem parte da organização.

De acordo Vieira e Gomes (2013), os VOs influenciam as ações de um indivíduo ou grupo e determinam a forma que cada indivíduo irá se comportar, agir e pensar. Do mesmo modo, os valores podem ser evidenciados nas organizações, influenciando o comportamento organizacional dos colaboradores.

Os VOs também são definidos como crenças que as pessoas influentes da empresa possuem, movidas pelo ambiente no qual estão inseridas, induzindo-os a presumir o que é melhor para a empresa [Tamayo e Gondim 1996]. Tamayo (1998) acrescenta a este pensamento que os valores organizacionais são definidos pelas características importantes identificadas de forma cognitiva (o que é ou não desejável na empresa), evidenciado pelas crenças de seus administradores ou pelo caminho que a organização optou para suas ações internas ou externas.

A empresa e o comportamento de seus colaboradores são orientados pelos VOs, permitindo delimitar a forma de agir, pensar e julgar dentro de um determinado grupo social. Dessa forma, os VOs são crenças que existem dentro da empresa, sendo compartilhadas e seguidas pelos colaboradores [Tamayo e Gondim 1996]. 


\subsection{Trabalhos relacionados}

A literatura tem apresentado diversos estudos sobre a percepção de valores organizacionais nos mais diversos setores, inclusive na área de TI, podendo-se destacar os trabalhos de Silva e Correia (2013), Siqueira e Vieira (2012), Correia (2015) e Lampkowski et al. (2016).

O trabalho de Silva e Correia, utilizou como base para a pesquisa a ferramenta Inventário de Valores Organizacionais (IVO), com intuito de analisar os VOs e o clima organizacional por meio da percepção dos funcionários de uma instituição de nível superior privada. A pesquisa foi aplicada a 41 funcionários utilizando os dois níveis de tipos motivacionais: reais e desejáveis. O primeiro resultado evidenciou que os funcionários atribuem importância maior a autonomia, o segundo resultado evidenciou que os funcionários tem uma percepção elevada para a hierarquia. Já o terceiro resultado mostrou uma diferença com valores não significativos, demonstrando um equilíbrio favorável ao sucesso da organização. Assim, instituição analisada estava atendendo às expectativas dos funcionários, tendo em vista que a pesquisa buscava analisar a satisfação no trabalho influenciada pelos VOs [Silva e Correia 2013].

O trabalho de Siqueira e Vieira (2012) teve como objetivo identificar a percepção de funcionários sobre os Vos. O estudo foi aplicado em uma empresa de serviços de manutenção e utilizou outro método como base para análise, a Escala de Valores Organizacionais (EVO) proposta por Tamayo e Gondim (1996). Essa pesquisa classificou os valores de acordo com uma comparação realizada entre fatores e valores corporativos gerais e setoriais da empresa distinguindo-os em: gestão executiva, líder, funcionários da sede e funcionários de Jundiaí. Os resultados obtidos mostraram uniformidade entre as percepções do grupo de valores classificados como gestão executiva, líder e funcionários de Jundiaí, porém houve divergências com relação aos valores reais e desejáveis, permitindo assim observar que a empresa prioriza aspectos relacionados a diretrizes e políticas e rejeita os aspectos individuais, evidenciando um conflito de VOs [Siqueira e Vieira 2012].

Amaral (2015) apresenta um modelo conceitual preliminar sobre a relação existente entre Cultura Organizacional (CO) e Metodologias Ágeis (MA). Para identificar como os conceitos de $\mathrm{CO}$ e MA se relacionam e de que modo as empresas podem alinhar os preceitos existentes, foi conduzido um Mapeamento Sistemático da Literatura (MSL). Como resultados obtidos, obteve-se a falta de práticas, guias, modelos, recomendações, técnicas, processos, e artefatos que efetivamente apoiem o processo de modificação de $\mathrm{CO}$ com o intuito de aproximá-la da filosofia ágil. Além disso, foram coletados os principais conceitos e resultados existentes na literatura relacionados a influência da adoção de MA na $\mathrm{CO}$ e a influencia da $\mathrm{CO}$ na condução de MA, para elaborar um modelo conceitual sobre $\mathrm{CO}$ no contexto de MA. Como resultado obteve-se a contribuição para a comunidade de SI por estruturar o conhecimento que está disseminado na literatura especializada, comunicando as percepções obtidas durante o estudo realizado em uma linguagem acessível para qualquer profissional da área de SI. No estudo apresentou-se um modelo conceitual sobre a relação entre $\mathrm{CO}$ e MA que contribui por apresentar os principais conceitos da área, dando um panorama sobre a relação entre os termos [Amaral 2015].

Lampkowski et al. (2016) realizou um estudo caracterizado como descritivo, que 
buscou analisar como os processos de gestão de pessoas e a cultura organizacional de uma empresa do ramo de TI necessitaram de adaptações para receber os colaboradores da geração Y. Utilizou-se a técnica do estudo de caso e, dentro do mesmo, a aplicação de entrevista e questionários para levantamento dos dados, além de utilizar abordagens qualitativa e quantitativa. A partir disso, verificou que há uma grande influência da CO nos colaboradores e que é o ambiente que influencia os mesmos e não os colaboradores que influenciam o ambiente da empresa. Além disso, observou que a organização estudada se preocupa em receber e reter os profissionais das gerações $\mathrm{X}$ e $\mathrm{Y}$ e que o tratamento é o mesmo para ambas [Lampkowski et al. 2016)].

Portanto, esta pesquisa se distinguiu dos trabalhos relacionados, primeiramente, pelas estratégias de identificação de VOs percebidos no ambiente acadêmico dentro do processo de formação, depois, pela população estudada, e, por último pela forma de analisar os resultados encontrados. O que se pode destacar é que todos os trabalhos relacionados obtiveram resultados com impacto a nível organizacional, enquanto esta pesquisa visa obter resultados com impacto no mercado e no nível de formação de futuros profissionais.

\subsection{Valores organizacionais em empresas de TI}

Os valores organizacionais (Vos) objeto de estudo deste trabalho de pesquisa, foram retirados do trabalho de Passos et al. (2013) que por meio de uma revisão sistemática identificou um conjunto de 40 VOs que podem caracterizar a cultura organizacional (CO) de uma empresa. Os VOs foram distribuídos em três categorias que representam o tipo de profissional da organização responsável pela sua implantação:

- Alta Gerência: representada pela alta gerência e executivos, com 20 VOs $(50 \%)$;

- Líderes de Projeto: representado por gerente de projeto e coordenador, com 7 VOs $(17 \%)$;

- Desenvolvedores: representados pela equipe técnica do projeto (projetistas, testadores, programadores e analistas), com 13 VOs (33\%).

Passos et al. (2013) identificou os principais VOs abordados na literatura existente. Em seguida, diante destes resultados, foi determinado um conjunto inicial de 40 VOs que poderiam caracterizar a cultura de uma empresa. Os VOs foram divididos nas três categorias citadas que representam o tipo de profissional da organização responsável por cada valor [Passos et al. 2013].

A pesquisa analisou 41 participantes a partir de seus respectivos perfis incluindo o nível de experiência, formação, conhecimento e tempo de atuação. Com os resultados obtidos foi analisada a importância dos VOs para caracterizar a CO de uma organização de software.

As respostas de cada participante geraram dados que permitiram indicar os VOs mais importantes (com $100 \%$ de nível de importância) para caracterização e identificação de sucesso em uma organização de software [Passos et al. 2013]. Assim, os valores foram ordenados do maior para o menor, conforme apresentado na Tabela 1 (os mais importantes são aqueles cuja variável tem os maiores valores) [Passos et al. 2013]. 
Tabela 1 - Relação dos VOs considerados importantes para o mercado

\begin{tabular}{|c|c|c|c|}
\hline \# & Cat & Valores Organizacionais & $\begin{array}{c}\text { Nível de } \\
\text { Importância }\end{array}$ \\
\hline $1^{\circ}$ & LP & Informação das decisões tomadas & $100,0 \%$ \\
\hline $2^{\circ}$ & $\mathrm{AG}$ & Política de compromisso com a qualidade dos produtos, serviços e processos & $100,0 \%$ \\
\hline $3^{\circ}$ & $\mathrm{DE}$ & Responsabilidades quanto a prazos e metas & $100,0 \%$ \\
\hline $4^{\circ}$ & $\mathrm{AG}$ & Sistema de remuneração adequado ao cargo ocupado & $100,0 \%$ \\
\hline $5^{\circ}$ & $\mathrm{AG}$ & Visão, metas e objetivos claros e estabelecidos & $100,0 \%$ \\
\hline $6^{\circ}$ & LP & Acompanhamento das atividades planejadas & $98,4 \%$ \\
\hline $7^{\circ}$ & $\mathrm{AG}$ & Capacidade de se auto reorganizar para mudanças & $98,4 \%$ \\
\hline $8^{\circ}$ & $\mathrm{AG}$ & Investimento em tecnologia e inovação & $97,0 \%$ \\
\hline $9^{\circ}$ & $\mathrm{DE}$ & Capacidade de se adaptar a mudanças & $96,6 \%$ \\
\hline $10^{\circ}$ & $\mathrm{DE}$ & Capacidade de trabalhar em grupo & $96,6 \%$ \\
\hline $11^{\circ}$ & $\mathrm{DE}$ & Envolvimento, comprometimento e participação & $96,6 \%$ \\
\hline $12^{\circ}$ & $\mathrm{DE}$ & Cooperativismo e colaborativismo & $96,5 \%$ \\
\hline $13^{\circ}$ & $\mathrm{AG}$ & Plano de gerenciamento estratégico & $96,3 \%$ \\
\hline $14^{\circ}$ & $\mathrm{DE}$ & Compartilhamento de valores, como respeito, lealdade e ética & $95,7 \%$ \\
\hline $15^{\circ}$ & $\mathrm{AG}$ & Investimento em cursos de aperfeiçoamento, capacitação e treinamento & $95,7 \%$ \\
\hline $16^{\circ}$ & $\mathrm{AG}$ & Nível de relacionamento entre os funcionários & $94,9 \%$ \\
\hline $17^{\circ}$ & AG & Valorizar e encorajar ideias criativas e inovadoras & $93,7 \%$ \\
\hline $18^{\circ}$ & $\mathrm{DE}$ & Participação na definição das metas e objetivos & $92,2 \%$ \\
\hline $19^{\circ}$ & $\mathrm{DE}$ & Facilidades de aceitação em relação às pessoas externas e novos funcionários & $91,4 \%$ \\
\hline $20^{\circ}$ & $\mathrm{DE}$ & Competência & $91,4 \%$ \\
\hline $21^{\circ}$ & $\mathrm{AG}$ & Estrutura organizacional definida & $91,3 \%$ \\
\hline $22^{\circ}$ & LP & Disponibilidade e acessibilidade & $90,8 \%$ \\
\hline $23^{\circ}$ & $\mathrm{AG}$ & Estratégia para gerenciamento dos riscos & $90,0 \%$ \\
\hline $24^{\circ}$ & LP & $\begin{array}{llllll}\begin{array}{l}\text { Levar em } \\
\text { funcionários }\end{array} & \text { consideração } & \text { as } & \text { questões } & \text { pessoais } & \text { dos } \\
\end{array}$ & $88,2 \%$ \\
\hline $25^{\circ}$ & $\mathrm{AG}$ & Estrutura de controle e comunicação interna & $85,7 \%$ \\
\hline $26^{\circ}$ & LP & Poder e liberdade de tomar decisão & $84,3 \%$ \\
\hline $27^{\circ}$ & $\mathrm{DE}$ & Protocolo para a realização das tarefas & $84,3 \%$ \\
\hline $28^{\circ}$ & $\mathrm{AG}$ & Plano de estratégia com relação a reparação de erros & $84,2 \%$ \\
\hline $29^{\circ}$ & $\mathrm{AG}$ & Regras específicas de como os funcionários têm acesso aos cargos & $84,2 \%$ \\
\hline $30^{\circ}$ & $\mathrm{AG}$ & Processo de tomada de decisão & $82,7 \%$ \\
\hline $31^{\circ}$ & $\mathrm{AG}$ & Foco no cliente & $81,9 \%$ \\
\hline $32^{\circ}$ & AG & 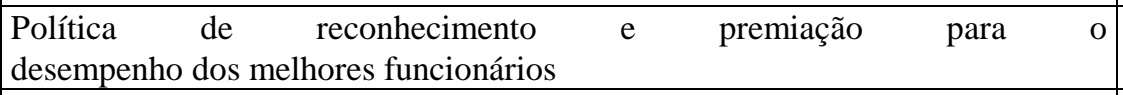 & $81,7 \%$ \\
\hline $33^{\circ}$ & $\mathrm{AG}$ & Personalidade de um membro da equipe & $78,0 \%$ \\
\hline $34^{\circ}$ & LP & Adoção de um estilo padrão de gestão & $76,8 \%$ \\
\hline $35^{\circ}$ & $\mathrm{DE}$ & Participação na tomada de decisão & $76,7 \%$ \\
\hline $36^{\circ}$ & $\mathrm{DE}$ & Concordância & $74,4 \%$ \\
\hline $37^{\circ}$ & $\mathrm{AG}$ & Regras definidas de competitividade & $72,9 \%$ \\
\hline $38^{\circ}$ & $\mathrm{DE}$ & Estabilidade no emprego & $64,3 \%$ \\
\hline $39^{\circ}$ & LP & Autoridade e hierarquia & $61,7 \%$ \\
\hline $40^{\circ}$ & AG & Resultados e lucros & $23,4 \%$ \\
\hline \multicolumn{4}{|c|}{ Legenda: \#: Classificação Cat: Categoria } \\
\hline
\end{tabular}

Fonte: Adaptado de Passos et al. (2013) 
Nesta pesquisa, somente a primeira fase do estudo de Passos et al. (2013) serviu como base para este estudo que trata-se do conjunto de valores organizacionais de empresas de software identificados (40 valores) e suas categorias (03 categorias) que permitiu a análise da percepção da comunidade acadêmica dos cursos de Sistema de Informação e Engenharia de Software sobre tais valores.

\section{Caminho percorrido}

A metodologia adotada nesta pesquisa consistiu em utilizar as abordagens qualitativa e quantitativa para: (a) investigar os VOs na percepção dos discentes; (b) investigar os VOs na percepção dos docentes e (c) analisar os VOs identificados nos PPPs dos cursos de SI e ES.

Para investigar a percepção dos discentes e docentes dos cursos de ES e SI foi aplicado um questionário para este público nos meses de junho a setembro de 2016 (por acessibilidade) totalizando 167 (82 discentes de ES e 85 discentes de SI) discentes do total de 292, validados um total de 158 questionários e 8 docentes do total de 10 . Também foi realizada uma entrevista com 5 docentes dos cursos de TI da universidade pesquisada.

Os participantes responderam o questionário que estava organizado em duas partes: a primeira com 4 questões relativas a VOs e a preparação dos discentes: (1) Você conhece algo sobre o tema "Valores Organizacionais (VOs)"? (Sim/Não); (2)Você acha que os VOs podem contribuir para o funcionamento de uma empresa de TI? (Sim/Não/Não sei responder); (3) Você conhece os VOs que as empresas de TI consideram importantes? (Sim/Não/Não sei responder); (4) O curso que você faz te prepara (Para ser líder de projeto/Assumir cargos na alta gerência/Para ser desenvolvedor/Outros/Não sei responder); e a segunda parte, para cada VO o participante respondeu o quanto o VO é percebido (em uma escala de 1 a 5) nos cursos (ES ou SI) e o quanto é importante (em uma escala de 1 a 5) para a formação do discente.

O tipo de entrevista definido para a pesquisa foi a semiestruturada descrita por Vergara (1998) como a que não deve sair do assunto central, mas que permite novos questionamentos dentro do objetivo central da pesquisa. No processo, seguiu-se um roteiro com 6 perguntas abertas: (1) $O$ que você entende que são valores organizacionais?; (2) Você conhece os valores organizacionais mais importantes para uma empresa de TI? Se sim, quais são?; (3) Os VOs são os mesmos para os diversos níveis de categoria (Líder de projeto, alta gerência e desenvolvedores)? Por quê?; (4) Quais os principais VOs de uma empresa de TI devem ser abordados no cursos de ES e SI (da universidade pesquisada)? (5) Os cursos de ES e SI preparam os discentes para o mercado de trabalho levando em consideração os VOs importantes? (6) O PPP dos cursos de ES e SI incorporam os VOs?. Esse processo de coleta teve uma duração média de 10 minutos cada entrevista.

No total, existem 10 docentes atuando na área de TI na universidade pesquisada. Deste total, 8 docentes participaram da pesquisa, sendo que 5 ([DO1], [DO2], [DO3], [DO4], [DO5]) responderam ambos os instrumentos (questionário e o roteiro de entrevista) e 3 ([DO6], [DO7], [DO8]) responderam somente o questionário. A caracterização dos participantes que responderam a entrevista consta na Tabela 2. 
Tabela 2 - Caracterização dos participantes que responderam a entrevista

\begin{tabular}{|c|c|c|c|c|c|}
\hline \multirow{2}{*}{ ID } & \multirow{2}{*}{$\begin{array}{l}\text { Formação } \\
\text { Acadêmica }\end{array}$} & \multicolumn{4}{|c|}{ Experiência (anos) } \\
\hline & & Líder de Projeto & Alta Gerência & Desenvolvedor & Docência \\
\hline$[\mathrm{DO} 1]$ & Especialização & - & - & Abaixo de 1 & Acima de 4 \\
\hline [DO2] & Mestrado & - & - & Entre 1 e 2 & Acima de 4 \\
\hline [DO3] & Mestrado & - & - & - & Entre 3 e 4 \\
\hline$[\mathrm{DO} 4]$ & Mestrado & - & Entre 3 e 4 & Entre 3 e 4 & Acima de 4 \\
\hline [DO5] & Mestrado & Entre 2 e 3 & Entre 1 e 2 & Entre 1 e 2 & Entre 2 e 3 \\
\hline$[\mathrm{DO6}]$ & Mestrado & Entre 2 e 3 & - & Entre 3 e 4 & Entre 2 e 3 \\
\hline [DO7] & Mestrado & Abaixo de 1 & - & Abaixo de 1 & Entre 2 e 3 \\
\hline$[\mathrm{DO} 8]$ & Mestrado & - & - & - & Entre 3 e 4 \\
\hline
\end{tabular}

Fonte: Dados da pesquisa (2016)

Os procedimentos para análise dos dados, após a obtenção dos resultados, foram realizados de forma distinta conforme descrito por instrumento de coleta:

a) Entrevista: neste instrumento foi empregada análise de conteúdo, que permite explorar os conhecimentos por trás de dados obtidos por meio da linguagem, obtendo assim como principal elemento da análise de conteúdo a fala [Bardin 2011];

b) Questionário: neste instrumento foi empregada análise a partir da estatística descritiva por meio do cálculo de frequências relativas para determinar o número de observações que tiveram as variáveis relativas e absolutas de forma a obter a proporção do número de ocorrências em uma determinada classe em relação ao total de observações. O objetivo deste foi investigar a percepção dos docentes quanto aos VOs abordados nos cursos de TI da universidade pesquisada, aplicando técnicas de acordo com os objetivos e planos da pesquisa [Gil 2002].

Para investigar os VOs nos PPPs dos cursos de ES e SI foi realizada uma análise dos documentos, por meio de uma leitura na íntegra de cada PPP. Após esta etapa, foram identificados, por meio de palavras-chaves, os trechos relacionados aos VOs. Além destes dados, também obteve-se o número de vezes que cada palavra-chave aparecia no documento, permitindo a análise. Em seguida, esses dados foram tabulados, de maneira a ordenar com valores numéricos para facilitar a leitura e análise.

Na análise, após a obtenção dos resultados, foram utilizadas além das palavraschaves, um identificador (entre colchetes) para cada um desses VOs identificados no trabalho de Passos et al. (2013), de forma que os VOs serão identificados ao longo das próximas seções tanto pelo ID (Identificador), quanto pela palavra-chave a ele relacionado. No Tabela 3 além dessas informações é apresentada as categorias no qual cada VO é associado e uma breve descrição dos mesmos. 
Tabela 3 - Palavras chave associadas aos valores organizacionais

\begin{tabular}{|c|c|c|c|}
\hline ID & Cat & Palavras-Chaves & Valores Organizacionais \\
\hline [1] & LP & Informação & Informação das decisões tomadas \\
\hline$[2]$ & $\mathrm{AG}$ & Qualidade & $\begin{array}{l}\text { Política de compromisso com a qualidade dos produtos, serviços e } \\
\text { processos }\end{array}$ \\
\hline$[3]$ & $\mathrm{DE}$ & Responsabilidade & Responsabilidades quanto a prazos e metas \\
\hline [4] & $\mathrm{AG}$ & Remuneração & Sistema de remuneração adequado ao cargo ocupado \\
\hline [5] & $\mathrm{AG}$ & Objetividade & Visão, metas e objetivos claros e estabelecidos \\
\hline$[6]$ & LP & Supervisão & Acompanhamento das atividades planejadas \\
\hline [7] & $\mathrm{AG}$ & Reorganização & Capacidade de se auto reorganizar para mudanças \\
\hline [8] & $\mathrm{AG}$ & Investimento & Investimento em tecnologia e inovação \\
\hline [9] & $\mathrm{DE}$ & Adaptação & Capacidade de se adaptar a mudanças \\
\hline$[10]$ & $\mathrm{DE}$ & Entrosamento & Capacidade de trabalhar em grupo \\
\hline [11] & $\mathrm{DE}$ & Comprometimento & Envolvimento, comprometimento e participação \\
\hline [12] & $\mathrm{DE}$ & Cooperação & Cooperativismo e colaborativismo \\
\hline [13] & $\mathrm{AG}$ & Gerenciamento & Plano de gerenciamento estratégico \\
\hline$[14]$ & $\mathrm{DE}$ & Compartilhamento & Compartilhamento de valores, como respeito, lealdade e ética \\
\hline [15] & $\mathrm{AG}$ & Capacitação & Investimento em cursos de aperfeiçoamento, capacitação e treinamento \\
\hline [16] & $\mathrm{AG}$ & Relacionamento & Nível de relacionamento entre os funcionários \\
\hline [17] & $\mathrm{AG}$ & Criatividade & Valorizar e encorajar ideias criativas e inovadoras \\
\hline$[18]$ & $\mathrm{DE}$ & Democracia & Participação na definição das metas e objetivos \\
\hline$[19]$ & $\mathrm{DE}$ & Aceitação & $\begin{array}{l}\text { Facilidades de aceitação em relação às pessoas externas e novos } \\
\text { funcionários }\end{array}$ \\
\hline [20] & $\mathrm{DE}$ & Competência & Competência \\
\hline [21] & $\mathrm{AG}$ & Organização & Estrutura organizacional definida \\
\hline [22] & LP & Disponibilidade & Disponibilidade e acessibilidade \\
\hline [23] & $\mathrm{AG}$ & Estratégia & Estratégia para gerenciamento dos riscos \\
\hline [24] & LP & Respeito & Levar em consideração as questões pessoais dos funcionários \\
\hline [25] & $\mathrm{AG}$ & Comunicação & Estrutura de controle e comunicação interna \\
\hline [26] & LP & Liberdade & Poder e liberdade de tomar decisão \\
\hline [27] & $\mathrm{DE}$ & Acompanhamento & Protocolo para a realização das tarefas \\
\hline [28] & $\mathrm{AG}$ & Planejamento & Plano de estratégia com relação a reparação de erros \\
\hline [29] & $\mathrm{AG}$ & Promoção & Regras específicas de como os funcionários têm acesso aos cargos \\
\hline [30] & $\mathrm{AG}$ & Decisão & Processo de tomada de decisão \\
\hline [31] & $\mathrm{AG}$ & Foco & Foco no cliente \\
\hline$[32]$ & $\mathrm{AG}$ & Premiação & $\begin{array}{l}\text { Política de reconhecimento e premiação para o } \\
\text { desempenho dos melhores funcionários }\end{array}$ \\
\hline [33] & $\mathrm{AG}$ & Personalidade & Personalidade de um membro da equipe \\
\hline [34] & LP & Administração & Adoção de um estilo padrão de gestão \\
\hline [35] & $\mathrm{DE}$ & Participação & Participação na tomada de decisão \\
\hline [36] & $\mathrm{DE}$ & Entendimento & Concordância \\
\hline [37] & $\mathrm{AG}$ & Competitividade & Regras definidas de competitividade \\
\hline [38] & $\mathrm{DE}$ & Estabilidade & Estabilidade no emprego \\
\hline [39] & LP & Hierarquia & Autoridade e hierarquia \\
\hline [40] & $\mathrm{AG}$ & Lucro & Resultados e lucros \\
\hline
\end{tabular}

Fonte: Dados da pesquisa (2016) 
A partir dos resultados obtidos, foi realizada uma análise das três perspectivas a fim de obter um estudo mais abrangente. Para isso, foi adotada uma abordagem que emprega a utilização de análise de perspectivas denominada Triangulação (Vergara, 2015).

Nessa análise, foram priorizadas 03 tipos de perspectivas, a saber: 1) Análise geral de triangulação a partir dos valores incidentes na pontuação 5 da escala ( 1 a 5$)$ do questionário aos discentes, docentes e a incidência no PPP de cada curso; 2) Uma análise de triangulação das visões a partir das frequências absolutas/relativas dos 10 valores de maiores pontuações nas perspectivas docentes e discentes de cada curso, bem como a incidência no PPP; e, 3) a análise de triangulação a partir dos valores hierarquicamente categorizados por Passos et al. (2013) de mais importantes no mercado a partir das triangulações anteriores.

\section{Resultados e discussões}

A coleta de dados realizada com os discentes dos cursos de ES e SI e os docentes da área de TI da universidade pesquisada, obteve um total de 176 questionários, no qual responderam questões relativas à sua percepção sobre os VOs e o nível de importância dos mesmos para a profissão.

\subsection{Análise de dados dos discentes do curso de ES}

Os resultados obtidos a partir das respostas da primeira parte do questionário aplicado aos discentes do curso de ES mostraram que este público respondeu "Sim" para as questões: (1) Você conhece algo sobre o tema VOs? (52 respostas - 66\%); (2) Você acha que os VOs podem contribuir para o funcionamento de uma empresa de TI? (58 respostas - 73\%); (3) Você conhece os VOs que as empresas de TI consideram importantes? (24 respostas - 30\%).

Na questão 4 (O curso que você faz te prepara para: Ser líder de projeto/Assumir cargos na alta gerência/Ser desenvolvedor?), era possível marcar mais de uma opção e a mais citada foi "Desenvolvedores" que alcançou um total de $21(26,5 \%)$ respostas, seguida da opção "Líder de Projeto/Alta Gerência/Desenvolvedores" com 17 (21,5\%) respostas.

Os resultados obtidos a partir das respostas da segunda parte do questionário aplicado aos discentes do curso de ES, mostraram que este público não percebe 35 dos 40 VOs que são considerados importantes para o mercado, pois os mesmos aparecem citados pelos discentes como "Não percebidos" (1, na escala de 1 a 5). Além disso, os discentes consideram como "Não Importantes" (1, na escala de 1 a 5) 26 VOs. Pode-se inferir que a visão do mercado (com relação a VOs), de acordo com a pesquisa de Passos et al. (2013), é diferente da visão dos discentes, já que a maioria dos VOs utilizados nesta pesquisa além de não serem percebidos pelos discentes também são considerados como não importantes.

Este contraste mostra que o curso de ES pode estar distante da perspectiva do mercado, quanto aos valores organizacionais sendo até mesmo controverso às Diretrizes Curriculares Nacionais (DCNs) para a área de computação no qual são abordadas as principais características do egresso do curso de ES. Essa diretriz retrata que o 
profissional, além possuir habilidades e competências específicas da área, deve também atender as necessidades do mercado no qual será inserido.

$\mathrm{Na}$ análise entre as categorias Alta Gerência (AG), Líder de Projeto (LP) e Desenvolvedores (DE), pode-se observar que na percepção dos discentes de ES quanto aos 35 VOs que aparecem na resposta "Não percebe" (1, na escala de 1 a 5), predominou a categoria AG (19 VOs), seguido de DE (11 VOs) e LP (5 VOs), quanto aos 26 VOs que aparecem na resposta "Não Importante" (1, na escala de 1 a 5), predominou a categoria AG (16 VOs) seguido de DE (6 VOs) e LP (4 VOs).

Deste modo, percebe-se que a maioria dos VOs não percebidos são ligados aos profissionais que representam a AG nas organizações. A importância da hierarquia, ligada especificamente a gerência, pode influenciar o comprometimento de colaboradores de uma empresa junto aos objetivos da organização [Tamayo et al. 2000].

Outra análise foi realizada apenas com os 5 VOs "Extremamente percebidos" (5, na escala de 1 a 5) e "Extremamente importantes" (5, na escala de 1 a 5) e pode-se observar a predominância da categoria Desenvolvedores. No entanto, os profissionais com formação na área de TI, em sua maioria, ocupam cargos de suporte técnico e gerentes de TI e devem assim possuir características não só técnicas, mas também um perfil de liderança, saber conduzir a equipe através da colaboração [Zanardi e Silveira 2015].

As DCNs abordam que os egressos do curso de ES devem saber aplicar processos, técnicas e procedimentos de construção, evolução e avaliação da qualidade de software, possuir habilidades multifuncionais, criar aplicar e validar princípios, padrões e boas práticas; criar modelos de desenvolvimento, identificar requisitos para todo o processo de projetar, desenvolver, implementar, verificar e documentar o desenvolvimento de software, e por fim, saber lidar com problemas, oportunidades de maneira inovadora (Brasil 2012).

\subsection{Análise de dados dos discentes do curso de SI}

Os resultados obtidos a partir das respostas da primeira parte do questionário aplicado aos discentes do curso de SI mostraram que este público respondeu "Sim" para as questões: (1) Você conhece algo sobre o tema VOs? (54 respostas - 68\%); (2) Você acha que os VOs podem contribuir para o funcionamento de uma empresa de TI? (57 respostas - 72\%); (3) Você conhece os VOs que as empresas de TI consideram importantes? (34 respostas - 43\%).

Na questão 4 (O curso que você faz te prepara para: Ser líder de projeto/Assumir cargos na alta gerência/Ser desenvolvedor?), era possível marcar mais de uma opção e a mais citada foi "Desenvolvedores" que alcançou um total de 20 (25\%) respostas, seguida da opção "Líder de Projeto/Alta Gerência/Desenvolvedores" com 14 (18\%) respostas.

Os resultados obtidos a partir das respostas da segunda parte do questionário aplicado aos discentes do curso de SI mostraram que este público não percebe nenhum dos 40 VOs que são considerados importantes para o mercado, pois todos os $40 \mathrm{VOs}$ aparecem citados pelos discentes como "Não percebidos" (1, na escala de 1 a 5). Além disso, os discentes consideram como "Não Importantes" (1, na escala de 1 a 5) 11 VOs. Estes dados são contrastantes com a pesquisa de Passos et al. (2013), no qual identificou 
os 40 VOs como mais importantes entre empresas do mercado de TI, sendo possível inferir a incompatibilidade de percepções dos públicos estudados.

A análise entre as categorias (AG, LP e DE), na percepção dos discentes de SI quanto aos VOs que aparecem nas respostas de "Não percebe", não foi realizada, pois todos os 40 VOs aparecem nas respostas para "Não percebidos" (1, na escala de 1 a 5). Quanto aos 11 VOs que aparecem na resposta "Não Importante" (1, na escala de 1 a 5), predominou a categoria AG (5 VOs), seguido de DE e LP (ambas com 3 VOs cada).

O que se pode inferir a partir desses dados é que o curso de SI, de acordo com a percepção dos discentes, pode não estar abordando ao longo do processo de formação nenhum dos VOs considerados importantes para o mercado, dentro das percepções analisadas. Além disso, os "Não importantes", por serem em sua maioria da categoria AG, mostram uma deficiência, na visão dos discentes, sobre à relevância do impacto que os VOs, relacionados a AG, podem exercer sobre a organização.

Outra análise foi realizada apenas com os 5 VOs "Extremamente percebidos" (5, na escala de 1 a 5) e "Extremamente importantes" (5, na escala de 1 a 5). Pode-se observar que as respostas de ambas as opções são predominantemente da categoria Desenvolvedores, o que é comum aos cursos de SI, pois os profissionais desta área muitas vezes acreditam que é necessário apenas qualificações ligadas ao domínio de ferramentas (desenvolvimento e banco de dados) [Rocha 2015]. No entanto Schuster (2008), acredita que este profissional deve ter uma visão mais generalista, visando também um contato mais direto com clientes e pensando em soluções para a organização.

As DCNs abordam que os egressos do curso de SI devem saber gerenciar os sistemas de informação dando suporte às atividades da organização garantindo a vantagem competitiva, partindo do pressuposto que o egresso é capaz de inovar, planejar e gerenciar a infraestrutura de tecnologia da informação em organizações [BRASIL 2012].

\subsection{Análise de dados dos docentes}

\subsubsection{Questionário}

Os resultados obtidos a partir das respostas da primeira parte do questionário aplicado aos docentes mostraram que este público respondeu "Sim" para as questões: (1) Você conhece algo sobre o tema VOs? (6 respostas - 75\%); (2) Você acha que os VOs podem contribuir para o funcionamento de uma empresa de TI? (7 respostas 87\%); (3) Você conhece os VOs que as empresas de TI consideram importantes? (5 respostas $-62 \%)$.

Na questão 4 (O curso prepara os discentes para: Ser líder de projeto/Assumir cargos na alta gerência/Ser desenvolvedor?), era possível marcar mais de uma opção e as mais citadas foram "Líder de Projeto/Desenvolvedores" e "Líder de Projeto/Alta Gerência/Desenvolvedores" que alcançaram um total de 2 (25\%) respostas, cada uma.

Os resultados obtidos a partir das respostas da segunda parte do questionário aplicado aos docentes mostraram que este público não percebe 11 dos 40 VOs que são considerados importantes para o mercado, pois os mesmos aparecem citados pelos 
docentes como "Não percebidos". Quanto a resposta "Não Importante" data pelos docentes nenhum VOs foi citado.

O que se pode inferir a partir desses dados é que os cursos de ES e SI, de acordo com a percepção dos docentes, podem não estar abordando alguns dos VOs considerados importantes para o mercado ou não estão sendo percebidos como tal. Quanto aos VOs "Não importantes", os docentes possuem uma visão semelhante ao mercado, tendo em vista que nenhum valor citado como "Não importante".

$\mathrm{Na}$ análise entre as categorias (AG, LP e DE), pode-se observar que na percepção dos docentes quanto aos 11 VOs que aparecem na resposta "Não percebe" (1, na escala de 1 a 5), predominou a categoria AG (9 VOs), seguido de DE (1 VO) e LP (1 VO), quanto aos VOs da resposta "Não Importante" (1, na escala de 1 a 5) não foi realizada análise, pois os docentes não marcaram nenhum VO como "Não Importante".

Outra análise foi realizada apenas com os 5 VOs "Extremamente percebidos" (5, na escala de 1 a 5) e "Extremamente importantes" (5, na escala de 1 a 5). Pode-se observar que as respostas de ambas as opções estão divididas entre as categorias LP e AG. Os VOs destas duas categorias são abordados na literatura como importantes para o bom funcionamento das organizações de TI, no qual os profissionais responsáveis por implantar esses VOs devem ser proativos e possuir características de liderança [Schuster 2008].

\subsubsection{Entrevista}

A análise realizada a partir das respostas das seis perguntas do roteiro de entrevista com os docentes permitiu observar que quando questionados sobre o seu entendimento acerca de VOs, existe uma definição em comum entre todos, no qual acreditam que esteja relacionado as atividades para o alcance dos objetivos ou sucesso de uma organização, ou seja, "define o sucesso para os empregados e estabelece os padrões que devem ser alcançados dentro de uma empresa" [DO2 2016]. Tamayo et al (2000) acreditam que os VOs podem influenciar a forma de agir e pensar dos colaboradores de uma organização e consequentemente as atividades que definidas para alcançar os objetivos.

Quando questionados sobre seu conhecimento quanto aos VOs mais importantes para uma empresa de TI, os docentes possuem uma visão mais voltada para liderança e comunicação, pois os mesmos acreditam que estes fatores podem "afetar direta ou indiretamente o processo" [DO5 2016]. Esse dois fatores podem ter forte influência na caracterização da organização quanto aos valores organizacionais, visto que a falta de diálogo entre colaboradores e a deficiência dos líderes na troca de informações com seus subordinados ao transmitir os VOs pode afetar objetivos da organização [Siqueira e Vieira 2012].

$\mathrm{Na}$ visão dos docentes nem todos os VOs são os mesmos para os diversos níveis de categoria (Líder de projeto, alta gerência e desenvolvedores) dentro de uma organização, visto que os docentes acreditam que alguns VOs podem ser específicos para cada nível, já que "uma parte podem ser iguais, mas deve ter alguns específicos para cada nível" [DO3 2016].

Quando questionados sobre os principais VOs que devem ser abordados nos cursos de TI os docentes concordam que deve ser priorizado o trabalho em equipe, pois 
acreditam que saber trabalhar em grupo é algo que deve ser aprendido no processo de formação, pois "todos estando comprometidos, dificilmente não vão chegar aos resultados esperado" [DO5 2016].

$\mathrm{Na}$ opinião dos docentes os cursos preparam os discentes para o mercado de trabalho, porém nem sempre levando em consideração os VOs importantes para este setor. Muitos acreditam que esse assunto ainda falta ser melhor explorado, já que tem "disciplinas que trabalham isso, mas outras tá faltando trabalhar mais esta questão".

Quando questionados se o PPP do cursos de ES e SI incorpora os VOs, os docentes ficaram dividos entre sim e não, e um docente acredita que "dentro do PPP ele tem essa proposta sim, mas depende de alguns fatores" [DO5 2016].

\subsection{Análise do PPP}

\subsubsection{Análise do PPP do curso de ES}

Esta etapa da pesquisa permitiu identificar trechos que mostram 12 VOs que estão explicitamente incorporados no PPP do curso de ES, incluindo ementas e objetivos das disciplinas. A Tabela 4 a seguir, apresenta a relação de 11 VOs identificados, com categoria, trechos extraídos do PPP bem como sua frequência.

\section{Tabela 4 - Trechos do PPP do curso de ES}

\begin{tabular}{|c|c|c|c|}
\hline VO & Cat. & Trechos que comprovam & $\begin{array}{l}\text { Frequência } \\
\text { absoluta }\end{array}$ \\
\hline$[2]$ & AG & $\begin{array}{l}\text { "desenvolver e efetuar manutenção de sistemas de software aplicando } \\
\text { tecnologias e práticas de gerência de projetos e outras disciplinas, } \\
\text { objetivando organização, produtividade e qualidade de software" p. } 2\end{array}$ & $1 / 34$ \\
\hline [3] & $\mathrm{DE}$ & "compreender e aplicar a ética e responsabilidade profissionais" p.80 & $1 / 8$ \\
\hline$[5]$ & AG & $\begin{array}{l}\text { "ter uma visão contextualizada da área de Sistemas de Informação em } \\
\text { termos políticos, sociais e econômicos" p. } 10\end{array}$ & $2 / 12$ \\
\hline [7] & $\mathrm{AG}$ & $\begin{array}{l}\text { "Recomenda-se que o egresso tenha condições de assumir um papel de } \\
\text { agente transformador do mercado, sendo capaz de provocar mudanças" p. } \\
8\end{array}$ & $2 / 4$ \\
\hline \multirow{2}{*}{ [10] } & \multirow{2}{*}{$\mathrm{DE}$} & $\begin{array}{l}\text { "Proporcionar condições para a formação do líder e o desenvolvimento de } \\
\text { habilidades para a capacitação do trabalho em equipe" p.7 }\end{array}$ & $3 / 3$ \\
\hline & & $\begin{array}{l}\text { "criar, liderar e participar de grupos com intuito de alcançar objetivos" } \\
\text { p.10 }\end{array}$ & $2 / 26$ \\
\hline$[12]$ & DE & $\begin{array}{l}\text { "procurar-se-á desenvolver posturas de cooperação, comunicação e } \\
\text { liderança" p.81 }\end{array}$ & $2 / 5$ \\
\hline \multirow[b]{2}{*}{ [14] } & \multirow[b]{2}{*}{ DE } & "atuar social e profissionalmente de forma ética" p. 10 & $3 / 21$ \\
\hline & & $\begin{array}{l}\text { "Preparar o educando para exercer a profissão com competência e ética } \\
\text { profissional" p. } 53\end{array}$ & $2 / 2$ \\
\hline [15] & AG & "assumir a postura de permanente busca de atualização profissional" p.80 & $3 / 5$ \\
\hline \multirow{2}{*}{ [17] } & \multirow{2}{*}{ AG } & $\begin{array}{l}\text { "ser criativo e inovador na proposição de soluções para os problemas e } \\
\text { oportunidades identificados nas organizações" p.10 }\end{array}$ & $1 / 1$ \\
\hline & & $\begin{array}{l}\text { "Desenvolver nos educandos a criatividade e o espírito crítico e } \\
\text { humanista" p. } 53\end{array}$ & $1 / 2$ \\
\hline [18] & DE & $\begin{array}{l}\text { "participar e conduzir processos de negociação para o alcance de } \\
\text { objetivos" p. } 10\end{array}$ & $1 / 8$ \\
\hline [25] & AG & $\begin{array}{l}\text { "expressar idéias de forma clara, empregando técnicas de comunicação } \\
\text { apropriadas para cada situação" p.10 }\end{array}$ & $3 / 19$ \\
\hline
\end{tabular}

Fonte: Dados da pesquisa (2016) 
Destes 11 valores organizacionais identificados como incorporados no PPP do curso, foram observados que $6(15 \%)$ são da categoria AG, ou seja, 30\% do total de VO da categoria foram identificados neste documento. Além disso, foram observados também que $4(10 \%)$ são da categoria Desenvolvedores, ou seja, 30,8\% do total de VO e para a categoria LP não foi identificado nenhum valor.

Abaixo estão os trechos que evidenciam os VOs incorporados nas ementas e objetivos das disciplinas. Essa busca permitiu identificar mais 2 VOs (VO [1] informação e VO [9] - adaptação) incorporado no ementário e objetivos das disciplinas de forma explícita, conforme explicita a Tabela 5 a seguir.

Tabela 5 - Trechos nas ementas e objetivos das disciplinas identificadas de ES

\begin{tabular}{|c|c|c|c|c|}
\hline VO & Cat. & $\begin{array}{c}\text { Disciplinas } \\
\text { identificadas }\end{array}$ & Ementa & Objetivo \\
\hline$[1]$ & LP & $\begin{array}{c}\text { Gestão das } \\
\text { Organizações }\end{array}$ & Tomada de Decisão & \\
\hline & & $\begin{array}{l}\text { Gestão das } \\
\text { Organizações }\end{array}$ & - & $\begin{array}{l}\text { "compreender os processos, operações e } \\
\text { atividades que pretendem maximizar os } \\
\text { resultados de modo sustentável" p. } 25\end{array}$ \\
\hline$[2]$ & $\mathrm{AG}$ & $\begin{array}{l}\text { Engenharia de } \\
\text { Software } 1\end{array}$ & - & $\begin{array}{l}\text { "utilização de ferramentas automatizadas } \\
\text { para a geração de sistemas, para tornar o } \\
\text { produto de software confiável, seguro e } \\
\text { menos dispendioso, minimizando o } \\
\text { tempo e os recursos direcionados para } \\
\text { sua manutenção" p. } 33\end{array}$ \\
\hline [9] & $\mathrm{DE}$ & $\begin{array}{l}\text { Gestão de } \\
\text { Equipes }\end{array}$ & $\begin{array}{l}\text { "processo de mudança } \\
\text { comportamental como agente de } \\
\text { mudança, frente aos processos } \\
\text { de mudança de base tecnológica } \\
\text { visando enfrentar e vencer } \\
\text { desafios" p. } 27\end{array}$ & - \\
\hline$[10]$ & $\mathrm{DE}$ & $\begin{array}{l}\text { Gestão de } \\
\text { Equipes }\end{array}$ & $\begin{array}{l}\text { "trabalho em grupo como } \\
\text { estratégia para o estabelecimento } \\
\text { de um relacionamento } \\
\text { interpessoal empático" p. } 27\end{array}$ & $\begin{array}{l}\text { "desenvolver habilidades básicas, para } \\
\text { lidar com grupos" p. } 27\end{array}$ \\
\hline$[14]$ & $\mathrm{DE}$ & Ética & $\begin{array}{l}\text { "Ética e Moral. Ética no mundo } \\
\text { contemporâneo. } \\
\text { profissional. } \\
\text { acadêmicas/profissionais } \\
\text { códigos de ética." p.29 }\end{array}$ & $\begin{array}{l}\text { "A disciplina deve capacitar o aluno a } \\
\text { exercer suas atividades profissionais } \\
\text { dentro dos princípios éticos } \\
\text { profissionais da área de Sistemas de } \\
\text { informação." p. } 29\end{array}$ \\
\hline
\end{tabular}

Fonte: Dados da pesquisa (2016)

$\mathrm{Na}$ disciplina Ética foi identificado um trecho relacionado ao VO [14] (Comprometimento). Este trecho está relacionado ao que é definido no Parecer CNE/CES n. ${ }^{\circ}$ 136/2012 Brasil (2012, p. 6) sobre o egresso saber criar sistemas de software de alta qualidade, eficaz e eficiente no contexto ético, social, legal e econômico.

Diante desses resultados, é possível observar que os VO [2] (Qualidade), 10 (Entrosamento) e [14] (Compartilhamento) estão presentes em diversas partes do PPP do curso, inclusive nas ementas e objetivos de 4 disciplinas $(7,4 \%$ do total de disciplinas obrigatórias ofertadas no curso de ES), como apresentado na Tabela 5. 
Outro ponto importante a salientar é que foram identificados os VOs incorporados no PPP do curso de Engenharia de Software em apenas 4 disciplinas, ou seja, 7,4\% do total de disciplinas obrigatórias ofertadas no curso de Engenharia de Software.

Dos 5 valores organizacionais foram identificados dentre as disciplinas, 1 (VO[2] - qualidade) é da categoria AG, 1 (VO [1] - informação) é da categoria LP e três (VO [9] - Adaptação, VO [10] - Entrosamento e VO [14] - Compartilhamento) são da categoria DE, evidenciando assim que o PPP do curso tem um foco maior nos VOs da categoria DE e estes correspondem a apenas $12 \%$ dos 40 VOs considerados importantes para o mercado.

No total, foram identificados 13 (30\% do total de 40 VOs) valores organizacionais incorporados no PPP do curso de ES, destes, foram observados que 6 (15\%) são da categoria Alta Gerência, ou seja, 30\% do total de VOs da categoria foram identificados neste documento. Além disso, foram observados também que 6 (15\%) são da categoria Desenvolvedores, ou seja, $46 \%$ do total de VOs da categoria Desenvolvedores. Para a categoria Líder de Projeto foi identificado apenas $1(2,5 \%)$ VO, ou seja, 14\% do total de VOs da categoria Líder de Projeto.

Diante do exposto evidencia-se que o PPP do curso de ES atende somente $30 \%$ do que o mercado considera importante, ou seja, baseando-se nas evidências encontradas nesta pesquisa, percebe-se a necessidade de uma reflexão crítica e profunda do PPP do curso de ES a cerca dos VOs considerados importantes para o mercado no qual o egresso deste curso irá atuar.

A literatura aborda que a necessidade da análise dos PPPs de cursos desta área se faz necessária continuamente buscando acompanhar a evolução desde mercado que se dá de forma muito rápida, provocando diversas mudanças no contexto econômico, na cultura, na educação e a sociedade como um todo (Hinterholtz et al, 2013).

\subsubsection{Análise do PPP do curso de SI}

Esta etapa da pesquisa permitiu identificar trechos que mostram 24 VOs que estão explicitamente incorporados no PPP do curso de SI, incluindo ementas e objetivos das disciplinas. A Tabela 6 a seguir, apresenta a relação de 17 VOs identificados, com categoria, trechos extraídos do PPP bem como sua frequência.

Tabela 6 - Trechos do PPP do curso de SI

\begin{tabular}{|c|c|l|c|}
\hline VO & Cat. & \multicolumn{1}{|c|}{ Trechos que comprovam } & $\begin{array}{c}\text { Frequência } \\
\text { Absoluta }\end{array}$ \\
\hline [2] & AG & $\begin{array}{l}\text { "Desenvolver a habilidade de avaliar um software de acordo com as normas de } \\
\text { qualidade segundo os padrões" p. 60 }\end{array}$ & $2 / 28$ \\
\cline { 3 - 5 } & $\begin{array}{l}\text { "alinhamento estratégico entre negócios e tecnologia da informação e dentro } \\
\text { de uma perspectiva de melhoria contínua dos processos e produtos } \\
\text { organizacionais" p.19 }\end{array}$ & $4 / 10$ \\
\hline$[5]$ & AG & $\begin{array}{l}\text { "ter uma visão contextualizada da área de Sistemas de Informação em termos } \\
\text { políticos, sociais e econômicos" p.23 }\end{array}$ & $4 / 19$ \\
\hline$[6]$ & LP & $\begin{array}{l}\text { "acompanhamento e monitoramento da implementação da estratégia da } \\
\text { organização" p.23 }\end{array}$ & $1 / 6$ \\
\hline$[7]$ & AG & $\begin{array}{l}\text { "Recomenda-se que o egresso tenha condições de assumir um papel de agente } \\
\text { transformador do mercado, sendo capaz de provocar mudanças" p. 14 }\end{array}$ & $3 / 13$ \\
\hline$[10]$ & DE & "formação do líder com capacidade de gerenciamento e o desenvolvimento de & $1 / 2$ \\
\hline
\end{tabular}




\begin{tabular}{|c|c|c|c|}
\hline & & \multicolumn{2}{|l|}{ habilidades para trabalhar em equipe" p. 24} \\
\hline & & $\begin{array}{lcccc}\text { "desenvolvimento de habilidades } & \text { de } & \text { relacionamento } & \text { interpessoal, } \\
\text { comunicação e trabalho em equipe" p. } 22 & & \\
\end{array}$ & $2 / 3$ \\
\hline & & "criar, liderar e participar de grupos com intuito de alcançar objetivos" p.23 & $2 / 18$ \\
\hline \multirow{2}{*}{ [13] } & \multirow{2}{*}{ AG } & $\begin{array}{l}\text { "gestão da incorporação destas tecnologias às estratégias, planejamento e } \\
\text { práticas organizacionais" p.19 }\end{array}$ & $2 / 22$ \\
\hline & & $\begin{array}{l}\text { "definição da estratégia de tecnologia da informação levando em conta seu } \\
\text { alinhamento com a estratégia de negócios da organização" p. } 19\end{array}$ & $6 / 15$ \\
\hline \multirow[b]{2}{*}{ [14] } & \multirow[b]{2}{*}{$\mathrm{DE}$} & "atuar social e profissionalmente de forma ética" p.23 & $1 / 15$ \\
\hline & & $\begin{array}{l}\text { "Preparar o educando para exercer a profissão com competência e ética } \\
\text { profissional" p. } 81\end{array}$ & $1 / 1$ \\
\hline [16] & AG & $\begin{array}{lccccc}\text { a } \quad \begin{array}{l}\text { formação } \\
\text { egressos dos complementar }\end{array} \begin{array}{c}\text { 'permite } \\
\text { com outras profissões' " p.16 }\end{array} & & \text { interação } & \text { dos } \\
\end{array}$ & $1 / 18$ \\
\hline \multirow{3}{*}{ [17] } & \multirow{3}{*}{ AG } & $\begin{array}{l}\text { "ser criativo e inovador na proposição de soluções para os problemas e } \\
\text { oportunidades identificados nas organizações" p. } 23\end{array}$ & $1 / 1$ \\
\hline & & "soluções necessárias à inovação e flexibilidade organizacionais" p.19 & $1 / 8$ \\
\hline & & $\begin{array}{l}\text { "Desenvolver nos educandos a criatividade e o espírito crítico e humanista" } \\
\text { p. } 81\end{array}$ & $1 / 12$ \\
\hline [18] & $\mathrm{DE}$ & $\begin{array}{l}\text { "participar e conduzir processos de negociação para o alcance de objetivos" } \\
\text { p. } 23\end{array}$ & $4 / 10$ \\
\hline [19] & $\mathrm{DE}$ & $\begin{array}{l}\text { "auxiliar os profissionais das outras áreas a compreenderem a forma com que } \\
\text { sistemas de informação podem contribuir para as áreas de negócio" p. } 23\end{array}$ & $2 / 5$ \\
\hline [20] & $\mathrm{DE}$ & $\begin{array}{l}\text { "Participar em projetos de consultoria organizacional, estágios } \\
\text { extracurriculares e visitas técnicas às organizações de trabalho, desenvolvendo } \\
\text { competências e percepções necessárias ao exercício da profissão" p. } 32\end{array}$ & $6 / 21$ \\
\hline [25] & AG & $\begin{array}{l}\text { "expressar ideias de forma clara, empregando técnicas de comunicação } \\
\text { apropriadas para cada situação" p. } 23\end{array}$ & $2 / 17$ \\
\hline [28] & $\mathrm{AG}$ & $\begin{array}{l}\text { "diagnosticar e mapear, com base científica, problemas e pontos de melhoria } \\
\text { nas organizações, propondo alternativas de soluções baseadas em sistemas de } \\
\text { informações" p. } 23\end{array}$ & $7 / 57$ \\
\hline [31] & $\mathrm{AG}$ & $\begin{array}{l}\text { "o profissional }[\ldots] \text { tem como responsabilidades: administrar ambiente } \\
\text { informatizado, prestando suporte técnico ao cliente" p. } 20\end{array}$ & $1 / 8$ \\
\hline [37] & $\mathrm{AG}$ & $\begin{array}{l}\text { "participar do desenvolvimento e implantação de novos modelos de } \\
\text { competitividade e produtividade nas organizações" p. } 22\end{array}$ & $1 / 4$ \\
\hline [39] & LP & $\begin{array}{l}\text { "é preciso considerar que os sistemas de informação fazem parte de um } \\
\text { contexto organizacional onde os usuários desempenham diferentes papéis, de } \\
\text { acordo com uma hierarquia que estrutura níveis de autoridade e } \\
\text { responsabilidade" p.7 }\end{array}$ & $1 / 3$ \\
\hline
\end{tabular}

Fonte: Dados da pesquisa (2016)

O trecho que apresentou maior frequência está relacionado ao VO [28] (Planejamento) da categoria Alta Gerência que aborda os planos estratégicos de reparação de erros. Nele evidencia-se que este valor organizacional encontra-se no item da importância de planos estratégicos baseados em sistemas de informações, a palavrachave utilizada pare este VO foi identificada neste contexto 7 vezes ao longo das 57 vezes que é citada em todo o PPP (Tabela 6).

No VO [5] (Objetividade), da categoria Alta Gerência, foi identificado o trecho relacionado aos objetivos e metas da organização. Nele é citado a importância de se ter uma visão contextualizada da área de SI em termos políticos, sociais e econômicos. A palavra-chave utilizada para este VO foi identificada neste contexto 4 vezes ao longo de 19 vezes que é citada em todo o PPP (Tabela 6). 
A seguir estão os trechos que evidenciam os VOs incorporados nas ementas das disciplinas. Essa busca permitiu identificar mais 4 VOs (VO [1] - informação , VO [27] - acompanhamento, VO[34] - administração e VO[35] - participação) incorporados no ementário das disciplinas de forma explícita, conforme Tabela 7 a seguir:

Tabela 7 - Trechos das ementas do PPP do curso de SI

\begin{tabular}{|c|c|c|c|c|}
\hline N. ${ }^{\mathbf{O}}$ & Disciplinas identificadas & VO & Cat. & Trecho da Ementa \\
\hline 1 & Tomada de Decisão & 1 & LP & $\begin{array}{l}\text { "Os conceitos, níveis e tipos de decisão nas organizações" } \\
\text { "Os modelos individuais de tomada de decisão" p. } 52\end{array}$ \\
\hline 2 & Administração de Pessoal & 39 & LP & $\begin{array}{l}\text { "O conceito e os objetivos da administração de recursos } \\
\text { humanos" p.54 }\end{array}$ \\
\hline 3 & Ética & 14 & $\mathrm{DE}$ & $\begin{array}{l}\text { "Ética e Moral. Ética no mundo contemporâneo. Ética } \\
\text { profissional. Associações acadêmicas/profissionais e } \\
\text { códigos de ética." p. } 67\end{array}$ \\
\hline \multirow{2}{*}{4} & \multirow{2}{*}{ Gestão da Informação } & \multirow{2}{*}{13} & \multirow{2}{*}{ AG } & $\begin{array}{l}\text { "Planejamento, implementação e avaliação de estratégias } \\
\text { na área de Sistemas de informação" p. } 44\end{array}$ \\
\hline & & & & $\begin{array}{l}\text { "Planejamento, implementação e avaliação de estratégias } \\
\text { na área de Sistemas de informação" p. } 44\end{array}$ \\
\hline 5 & $\begin{array}{l}\text { Organização, Sistemas e } \\
\text { Métodos }\end{array}$ & 27 & DE & $\begin{array}{l}\text { Metodologias, técnicas e ferramentas de mapeamento e } \\
\text { melhoria de processos." p. } 48\end{array}$ \\
\hline 6 & $\begin{array}{l}\text { Sistema de Apoio a } \\
\text { Decisão }\end{array}$ & 35 & $\mathrm{DE}$ & $\begin{array}{l}\text { "Desenvolvimento de sistemas de informação de suporte ao } \\
\text { processo decisório tático e estratégico" p. } 56\end{array}$ \\
\hline \multirow{3}{*}{7} & \multirow{3}{*}{$\begin{array}{l}\text { Teoria Geral da } \\
\text { Administração }\end{array}$} & 10 & $\mathrm{DE}$ & "Enfoques Humano e Comportamental" \\
\hline & & 19 & $\mathrm{DE}$ & $\begin{array}{l}\text { "Escola de Relações Humanas, as decorrências da Escola } \\
\text { de Relações Humanas e a Escola Comportamentalista" p. } \\
37\end{array}$ \\
\hline & & 34 & LP & $\begin{array}{l}\text { "Abordagens Estruturalistas e do Desenvolvimento } \\
\text { Organizacional; Teorias Integrativas: Sistêmicas e } \\
\text { Contingenciais" p. } 37\end{array}$ \\
\hline
\end{tabular}

Fonte: Dados da pesquisa (2016)

A seguir estão os trechos que evidenciam os VOs incorporados nos objetivos das disciplinas. Essa busca permitiu identificar mais 3 VOs (VO [23] - Estratégia, VO[26] liberdade e $\mathrm{VO}[30]$ - decisão) incorporados nos objetivos das disciplinas de forma explícita de acordo com a Tabela 8:

Tabela 8 - Trechos dos objetivos do PPP do curso de SI

\begin{tabular}{|c|c|c|c|l|}
\hline N. & $\begin{array}{c}\text { Disciplinas } \\
\text { identificadas }\end{array}$ & VO & Cat. & \multicolumn{1}{|c|}{ Trecho do Objetivo } \\
\hline 1 & $\begin{array}{c}\text { Introdução aos } \\
\text { Sistemas de } \\
\text { Informação }\end{array}$ & 1 & LP & $\begin{array}{l}\text { "Abordar os conteúdos que fundamentam a área de Sistemas de } \\
\text { Informação, envolvendo os conceitos de dado, informação, } \\
\text { conhecimento, sistemas de informação e tecnologia da informação" } \\
\text { p. 39 }\end{array}$ \\
\hline 2 & $\begin{array}{c}\text { Administração de } \\
\text { Pessoal }\end{array}$ & 39 & LP & $\begin{array}{l}\text { "Identificar os processos que envolvem o gerenciamento de recursos } \\
\text { humanos e a aplicação dos sistemas de informação no contexto } \\
\text { organizacional da administração de pessoal." p.54 }\end{array}$ \\
\hline 3 & $\begin{array}{c}\text { Comportamento } \\
\text { Organizacional }\end{array}$ & 7 & AG & $\begin{array}{l}\text { "aspectos relacionados à gestão das mudanças organizacionais } \\
\text { decorrentes da implementação da tecnologia da informação nos } \\
\text { processos de negócios" p. 74 }\end{array}$ \\
\hline
\end{tabular}




\begin{tabular}{|c|c|c|c|c|}
\hline & & 31 & AG & $\begin{array}{l}\text { "Compreender os aspectos relacionados ao comportamento } \\
\text { individual e em grupo nas organizações no que tange ao } \\
\text { relacionamento entre os profissionais de sistemas de informação e os } \\
\text { usuários" p. } 74\end{array}$ \\
\hline 4 & $\begin{array}{l}\text { Engenharia de } \\
\text { Software } 1\end{array}$ & 2 & $\mathrm{AG}$ & $\begin{array}{l}\text { "Conhecer e aplicar técnicas avançadas de especificação de } \\
\text { requisitos, análise e projeto de sistemas, e a utilização de } \\
\text { ferramentas automatizadas para a geração de sistemas" p.53 }\end{array}$ \\
\hline 5 & $\begin{array}{l}\text { Gestão da } \\
\text { Informação }\end{array}$ & 13 & AG & $\begin{array}{l}\text { "Compreender o estudo dos modelos, métodos e técnicas para o } \\
\text { planejamento, direção, organização e avaliação da função de } \\
\text { Sistemas de Informação nas organizações" p. } 44\end{array}$ \\
\hline 6 & $\begin{array}{l}\text { Gestão da } \\
\text { Qualidade de } \\
\text { Software }\end{array}$ & 2 & $\mathrm{AG}$ & $\begin{array}{l}\text { "Desenvolver a habilidade de avaliar um software de acordo com as } \\
\text { normas de qualidade segundo os padrões:" p. } 60\end{array}$ \\
\hline 7 & $\begin{array}{l}\text { Organização, } \\
\text { Sistemas e Métodos }\end{array}$ & 34 & LP & $\begin{array}{l}\text { "Abordar aspectos relacionados á modelagem de negócios e } \\
\text { racionalização de processos no âmbito organizacional, estudando } \\
\text { modelos e técnicas para análise de modelos organizacionais" p. } 48\end{array}$ \\
\hline \multirow[b]{2}{*}{8} & \multirow[b]{2}{*}{$\begin{array}{l}\text { Sistema de Apoio a } \\
\text { Decisão }\end{array}$} & 34 & LP & $\begin{array}{l}\text { "Aplicar os princípios dos sistemas de informação de apoio ao } \\
\text { processo decisório estratégico e tático nas organizações" p. } 56\end{array}$ \\
\hline & & 1 & LP & $\begin{array}{l}\text { "Compreender o processo decisório organizacional, os diferentes } \\
\text { níveis de decisão organizacional e sua relação com os diversos tipos } \\
\text { de sistemas de informação" p. } 52\end{array}$ \\
\hline \multirow{2}{*}{9} & \multirow{2}{*}{$\begin{array}{l}\text { Teoria Geral da } \\
\text { Administração }\end{array}$} & 5 & AG & $\begin{array}{l}\text { "proporcionar uma visão global e integrada das principais áreas } \\
\text { funcionais da organização moderna" p. } 37\end{array}$ \\
\hline & & 16 & AG & $\begin{array}{l}\text { "Enfoques Humano e Comportamental, que englobam as Teorias } \\
\text { Transitivas, a Escola de Relações Humanas" p. } 37\end{array}$ \\
\hline \multirow{3}{*}{10} & \multirow{3}{*}{ Tomada de Decisão } & 23 & AG & $\begin{array}{l}\text { "teorias e métodos aplicáveis á análise de decisões sob condições } \\
\text { determinísticas e sob condições de risco" p. } 52\end{array}$ \\
\hline & & 26 & LP & $\begin{array}{l}\text { "Compreender o processo decisório organizacional, os diferentes } \\
\text { níveis de decisão organizacional e sua relação com os diversos tipos } \\
\text { de sistemas de informação" p. } 52\end{array}$ \\
\hline & & 30 & AG & $\begin{array}{l}\text { "teorias e métodos aplicáveis á análise de decisões sob condições } \\
\text { determinísticas e sob condições de risco." p. } 52\end{array}$ \\
\hline
\end{tabular}

Fonte: Dados da pesquisa (2016)

Assim, foram identificados 24 (60\% dos 40 VOs) valores organizacionais incorporados no PPP do curso de SI. Deste total, foram observados que 12 são da categoria AG, 7 são da categoria DE e 5 são da categoria LP. Diante do exposto evidencia-se que o PPP do curso de SI atende a $60 \%$ do que o mercado considera importante quanto a VOs, dentre eles a maioria relacionados a informação e tomada de decisão, ou seja, baseando-se nas evidências encontradas nesta pesquisa, percebe-se que o PPP do curso de SI possui um olhar direcionado para o mercado, ainda que a quantidade de VOs identificados no PPP não tenham sido ainda o mais adequado ao que se espera do curso.

A literatura aborda que o profissional de SI deve está engajado não somente nas práticas e aplicações da área, mas em todos os objetivos, buscando sempre soluções para chegar ao sucesso. Isso se deve ao domínio da informação e das tomadas de decisões [Bazzotti e Garcia 2006]. 


\subsection{Triangulação}

Para se obter a triangulação a partir das três perspectivas (Discentes, Docentes e PPP) foram relacionados os VOs considerados importantes por discentes e docentes e os VOs identificados nos PPPs dos cursos de TI.

Na primeira perspectiva, realizou-se uma análise geral de triangulação a partir dos valores incidentes na escala 5 (Extremamente importante) do questionário aos discentes, docentes e a incidência no PPP de cada curso. Obteve-se como resultado para o curso de ES a identificação de $100 \%$ dos VOs na percepção dos discentes e docentes; e 12 VOs no PPP do curso; enquanto que para o curso de SI obteve-se a identificação de $100 \%$ dos VOs na percepção dos discentes e docentes; e 24 VOs no PPP do curso. O que resulta em um total de 9 VOs que incidem entre as visões: discentes (ES e SI), docentes e os VOs identificados nos PPPs (ES e SI), onde a maioria são da categoria $\mathrm{AG}$, conforme figura 1 a seguir:
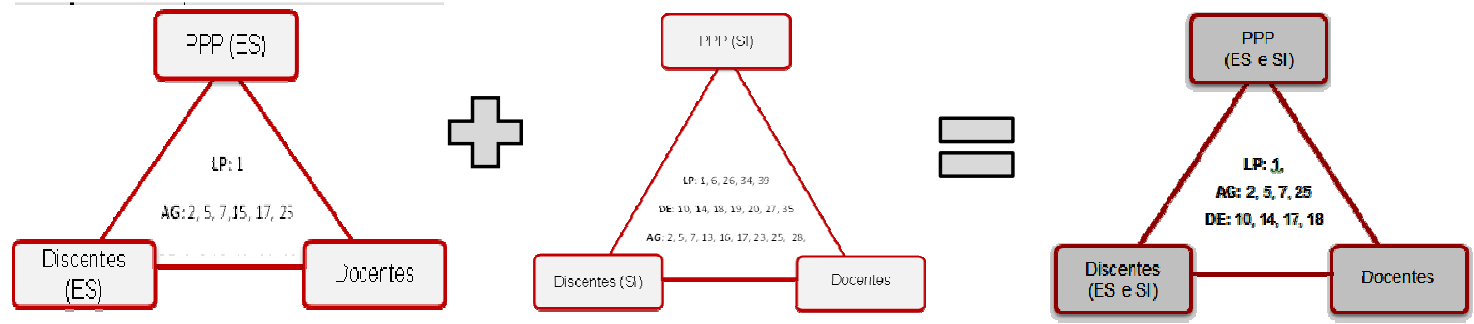

Figura 1. Análise da triangulação dos VOs incidentes na escala 5

$\mathrm{Na}$ segunda perspectiva, realizou-se uma análise de triangulação das visões a partir das frequências absolutas/relativas dos 10 valores de maiores pontuações nas perspectivas docentes e discentes de cada curso, bem como a incidência no PPP. Obteve-se como resultado para o curso de ES, na percepção dos docentes, discentes e incidencia no PPP os VOs [3], [7], [10], [14] e [17]. Para o curso de SI, na percepção dos docentes, discentes e incidencia no PPP, obteve-se a identificação dos VOs [7], [10], [14], [17] e [20], o que resulta em um total de 4 VOs ([7], [17], [10] e [14]) que incidem entre as visões: discentes (ES e SI), docentes e os VOs identificados nos PPPs (ES e SI), onde metade são da categoria AG e metade são da categoria DE, conforme exposto na figura 2 a seguir:
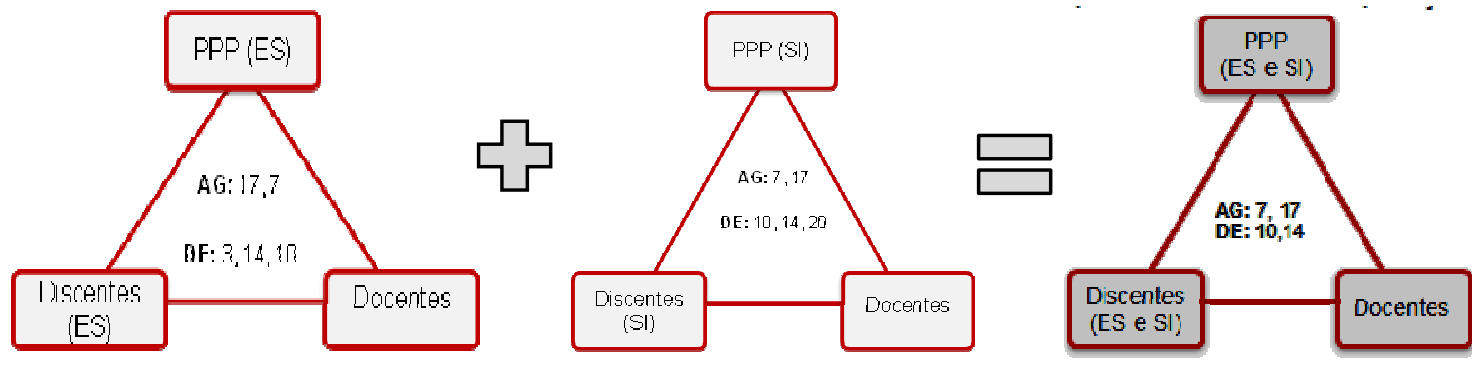

Figura 2. Análise da triangulação dos 10 VOs com maiores pontuação [5]

$\mathrm{Na}$ terceira perspectiva, realizou-se uma análise de triangulação a partir dos valores hierarquicamente categorizados por Passos et al. (2013) de mais importantes no mercado a partir das triangulações anteriores. Obteve-se como resultado para os cursos 
de ES e SI, na percepção dos docentes, discentes e incidencia no PPP, a identificação dos VOs [1], [2], [5], [7] e [10], onde a maioria são da categoria AG, conforme figura 3.

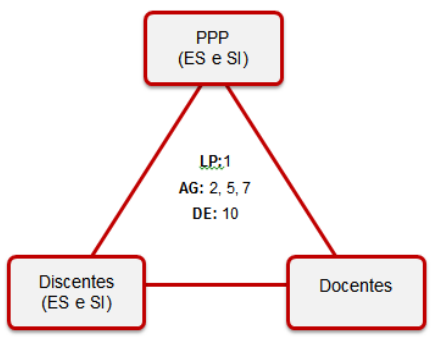

Figura 3. Análise da triangulação dos VOs hierarquicamente categorizados

A partir desses resultados pode-se inferir que os cursos (ES e SI) podem estar formando profissionais com visões díspares daquilo que o mercado considera importante. Na hierarquia de Passos et al. (2013) do total dos 10 VOs mais importantes, 2 são da categoria Líder de Projeto, 3 são da categoria Desenvolvedores e 5 são da categoria Alta Gerência. Essa disparidade se dá tanto na ausência da categoria Líder de Projeto quanto da ênfase dada pelos cursos a categoria desenvolvedores em detrimento da categoria Alta Gerência

É possível observar a predominância da categoria AG (Alta Gerência) nas três perspectivas (visões). A literatura aborda que no mercado, é cada vez mais comum os profissionais da área de TI se especializarem mais nas áreas de gestão. Já na área de gerência, o que é mais comum é que os profissionais dessa área sejam mais generalistas e não possuam conhecimento técnico profundo mostrando similaridades entre essas duas áreas. No entanto, mesmo que as organizações percebam a importância destas áreas para o mercado, os profissionais com foco mais especialistas ainda demonstram certa relutância às duas categorias.

\section{Considerações}

O mercado de TI exige dos profissionais não somente uma qualificação formal, mas competências, habilidades e que também saibam adequar os valores pessoais aos da organização (Schuster, 2008). Assim, os valores organizacionais podem influenciar as decisões tomadas dentro de uma organização e consequentemente determinar sucesso ou fracasso da mesma.

Este é um fator que pode ser trabalhado desde a fase de formação do profissional de TI. Por este motivo, o objetivo deste trabalho consistiu na análise da percepção da comunidade acadêmica dos cursos de SI e ES da universidade pesquisada sobre os valores organizacionais considerados como importantes para as empresas de software. De modo a alcançar o objetivo proposto, a metodologia aplicada foi estruturada de acordo com os objetivos específicos, considerando a visão dos discentes, docentes e a análise do PPP de cada um dos cursos citados.

A visão dos docentes quanto aos VOs percebidos nos cursos trouxe como resultado que este público não percebe 11 dos 40 VOs permitindo assim, inferir que os cursos de ES e SI podem não estar abordando alguns dos VOs considerados importantes para o mercado ou não estão sendo percebidos pelos atores pesquisados. Quanto aos valores organizacionais da resposta "Não importante", os docentes possuem uma visão semelhante ao mercado, tendo em vista que nenhum valor citado foi considerado como 
não importante. Para as respostas "Extremamente percebidos" e "Extremamente importantes" (5, na escala de 1 a 5), ambas as opções estão divididas entre as categorias "Líder de Projeto" e "Alta Gerência".

A percepção dos discentes do curso de ES mostraram que este público não percebe 35 dos 40 VOs e consideram como "Não Importantes" 26 VOs. Evidencia-se que a visão do mercado (com relação a VOs), de acordo com a pesquisa de Passos et al. (2013), é diferente da visão dos discentes, já que a maioria dos 40 VOs além de não serem percebidos pelos discentes também são considerados como não importantes. Para as respostas "Extremamente percebidos" e "Extremamente importante" (5, na escala de 1 a 5), para ambas as opções a categoria "Desenvolvedores" é predominante.

Partindo para análise do PPP do curso de ES, os principais resultados foram a identificação de 12 VOs distribuídos em $46 \%$ da categoria "Alta Gerência", $46 \%$ são da categoria "Desenvolvedores" e 8\% são da categoria "Líder de Projeto". De acordo com as DCNs da área de computação o curso de ES deve abranger diferentes ênfases. A origem dessas disciplinas pode ter como motivação diferentes classificações didáticas: aspectos gerenciais, aspectos técnicos, aspectos teóricos e aspectos experimentais [Brasil 2012].

A percepção dos discentes do curso de SI mostraram que este público não percebe nenhum dos 40 VOs e consideram como "Não Importantes" (1, na escala de 1 a 5) 11 VOs. Evidencia-se que o curso de SI pode não estar abordando ao longo do curso nenhum dos VOs considerados importantes para o mercado ou ainda não estão sendo percebidos pelos atores pesquisados como tal. Além disso, os "Não importantes", são em sua maioria da categoria Alta Gerência. Para as respostas "Extremamente Percebidos" (5, na escala de 1 a 5 )e "Extremamente importante" (5, na escala de 1 a 5) para ambas as opções a categoria predominante é "Desenvolvedores".

Partindo para análise do PPP do curso de SI, os principais resultados foram a identificação de 24 VOs distribuídos em $50 \%$ da categoria "Alta Gerência", $21 \%$ de "Líder de Projeto" e 29\% são da categoria "Desenvolvedores", o qual pode-se inferir uma relação com as orientações das DCNs da área de computação que definem que o curso de SI deve possibilitar não somente uma formação tecnológica, mas também que abranja diferentes ênfases, motivadas por diferentes classificações didáticas, como aspectos gerenciais, técnicos, teóricos e experimentais, que envolvam produção, marketing, recursos humanos e finanças [Brasil 2012].

Na primeira perspectiva de triangulação que teve como objetivo analisar os 5 valores organizacionais mais importantes dos cursos de ES e SI, obteve-se um total de 9 VOs que incidem nas três visões dos dois cursos, sendo $56 \%$ da categoria "Alta Gerência", $11 \%$ de "Líder de Projeto" e 33\% são da categoria "Desenvolvedores".

Já na segunda perspectiva, foram identificados os 10 VOs mais importantes com maiores frequências de cada curso. Obteve-se como resultado $50 \%$ da categoria "Alta Gerência" e 50 \% são da categoria "Desenvolvedores".

$\mathrm{Na}$ última perspectiva do processo de triangulação foram comparados os VOs mais importantes em cada curso e na universidade pesquisada em relação a hierarquização de Passos et al. (2013) o qual obteve-se como resultado 5 valores 
organizacionais, sendo 60\% da categoria "Alta Gerência", 20\% de "Líder de Projeto" e $20 \%$ são da categoria "Desenvolvedores".

Esta pesquisa traz a perspectivas de discentes e docentes de curso de TI sobre os VOs considerados importantes para o mercado. Embora este setor passe constantemente por mudanças e transformações, os VOs permanecem influenciando as atividades desenvolvidas dentro das organizações e o mercado continua a esperar dos egressos dos cursos da área de TI (futuros profissionais da área) saibam compartilhar valores dentro da organização, utilizando-os como uma ferramenta para as tomadas de decisões [Bucheroni 2012].

Como limitação do método, não foi possível alcançar a população total de discentes e docentes da comunidade acadêmica dos cursos de Engenharia de Software e Sistemas de Informação, tendo em vista que poderia demandar um tempo maior do que foi definido para esta pesquisa, além de não ser possível ter acesso a toda a população definida para o estudo.

Por fim, espera-se como trabalhos futuros uma análise dos VOs que podem estar implícitos na didática e em outros documentos do curso, relacionados à projetos de pesquisa e extensão, entre outros, assim como também uma análise do nível de adequação dos PPPs dos cursos de Engenharia de Software e Sistemas de Informação em relação aos VOs requeridos pelo mercado de TI; pesquisar sobre possíveis práticas pedagógicas que incentivem o desenvolvimento de competências que abordam valores importantes para o mercado.

\section{Referências}

Bardin, L. (2011) Análise de Conteúdo. Tradução Luís Antero Reto, Augusto Pinheiro. São Paulo: Edições 70.

Bazzotti, C. e Garcia, E. (2007) A importância do sistema de informação gerencial para a tomada de decisões. VI Seminário do Centro de Ciências Sociais Aplicadas de Cascavel, Paraná.

Brasil (2012). Emendas Constitucionais no 1/1992 a 68/2011 pelo Decreto Legislativo no 186/2008 e pelas Emendas Constitucionais de Revisão nos 1 a 6/1994. 35a. Constituição da República Federativa do Brasil. - 35. ed. - Brasília: Câmara dos Deputado. Edições Câmara, p. 446. Brasília.

Brasscom (2015). O Mercado de Profissionais de Tecnologia da Informação e Comunicação no Brasil: uma análise do período de 2006 a 2013. Disponível em: http://www.brasscom.org.br/brasscom/Portugues/download.php?cod=1775.

Bucheroni, C. A. (2012) Influências da Percepção de Valores Organizacionais dos Profissionais que Atuam com Gerência de Projetos Sobre seu Comportamento na Organização, 2012. 95 f. Dissertação (Mestrado Profissional em Administração)Centro de Pós-Graduação, Universidade Nove de Julho, São Paulo.

Castro, E. B. e Sá, M. A. D. (2002) Habilidades, Competências, Valores e Atitudes Um Perfil Para o Profissional de Computação e Informática. In Workshop de Educação em Informática, 10, 2002, Florianópolis: Sociedade Brasileira de Computação. 
Correia, G., P. Amaral, J., Graciano Neto, V. V., Gomes, P. (2015). Cultura Organizacional na Adoção de Metodologias Ágeis no Desenvolvimento de Sistemas de Informação: rumo a um Modelo Conceitual à Luz de um Estudo Sistemático. In III Workshop de Iniciação Científica em Sistemas de Informação, p. 1-4, Goiânia, Brasil.

Correia, J.C. P. (2013). A representação social do CIO no Brasil na percepção dos profissionais de Tecnologia da Informação. 2013. f. 124. Dissertação (Mestrado Executivo em Gestão Empresarial)-Escola Brasileira de Administração Pública e de Empresas, Centro de Formação Acadêmica em Gestão Empresarial. Rio de Janeiro.

Denizot, A. E. R. (2014). As pequenas empresas de tecnologia da informação e comunicação do estado do Rio de Janeiro à luz do radar da inovação: identificação e análise dos principais obstáculos para os processos de inovação. Revista Eletrônica Sistemas \& Gestão. p. 394-405. v9. n3.

Fernandes, P. G. (2010) Cultura Organizacional como Apoio à Institucionalização de Processos de Software Cultura Organizacional como Apoio à Institucionalização de Processos de Software. 2010. 203 f. (Dissertação Mestrado em computação) Universidade Federal de Goiás - - Instituto de Informática, Goiânia.

Freitas, M. E. (1991) Cultura Organizacional: Grandes Temas em Debate. Revista de Administração de Empresas, v. 31, n. 3, p. 73-82, jul/set.

Gaspar et al. (2016). Gestão do conhecimento em empresas atuantes na indústria de software no Brasil: um estudo das práticas e ferramentas utilizadas. Inf. \& Soc.:Est., João Pessoa, v.26, n.1, p. 151-166, jan./abr.

Gil, A. C. (2002) Como Elaborar Projeto de Pesquisa. 4. ed. São Paulo: Atlas.

Hinterholz Junior, O., Valenzuela, G. M., Silva, W. A. e Freire, A. A. C. (2013) Habilidades e Competências requeridas ao Profissional de TI : um olhar no Extremo Norte. In Congresso da Sociedade Brasileira de Computação, 33, 2013. p. 691-700, SBC, p. 691-700.

Hofstede, G., Neuijen, B., Ohayv, D. e Sanders, G. (1990) Measuring organizational cultures: a qualitative and quantitative study across twenty cases. Administrative Science Quarterly. v. 35, p. 286 -316.

Lampkosski, M., et al (2016) A. Impacto da geração Y nos processos de gestão de pessoas e na cultura organizacional; um estudo de caso em empresa de tecnologia da informação. Revista de FATEC-REFAS, v. 3, n. 1, out.

Macedo, S. M. S. e Barbosa, R. R. (2013) Gestão da informação, da tecnologia da informação e comportamentos e valores relativos à informação em Instituições de Ensino Superior (IES) de Belo Horizonte. BJIS, Marília (SP), v.7, n. Especial, p.137153, $1^{\circ} \quad$ Sem. Disponível em:http://www2.marilia.Unesp.br/revistas/index.php/bjis/index>.

Machado, D., Santos, A. e Pinto, V. (2009) Dimensões da Cultura Organizacional no Modelo de Hofstede: Aplicações em Uma Organização Militar do Exército Brasileiro e Um Órgão Público do Poder. Seminários em Administração, n. 1980. 
Mangia, U. B. (2013) Antecedentes à transição de carreira na área de tecnologia da informação. 2013. f. 73. Dissertação (Mestrado Executivo em Gestão Empresarial)Escola Brasileira de Administração Pública e de Empresas, Centro de Formação Acadêmica em Gestão Empresarial, Fundação Getúlio Vargas. Rio de Janeiro.

Oliveira, M. A. G., (1988) Como entender a cultura organizacional, São Paulo: Nobel.

Passos, O.; Dias-Neto, A.; Barreto, R. (2013) Relevant Organizational Values in the Implementation of Software Process Improvement Initiatives. CLEI Electronic Journal, v. 16, n. 1.

Peixoto, P. R. P. e Motta, A. L. T. S. (2012) Cultura e Valores Organizacionais como Ferramentas de Mudanças: Estudo de Caso em uma Empresa de Energia. VIII Congresso Nacional de Excelência em Gestão, jun.

Robbins, S. P. (2005) Comportamento organizacional. 11 ed. São Paulo: Peasonn Prentice Hall.

Rocha, E. C. F. (2015) Qualificação e reconhecimento de profissionais de Sistemas de Informação. XI Brazilian Symposium on Informarion System, p. 596-602, 26. maio. Goiânia.

Schein, E. H. (1992) Organizational culture and leadership. 2 ed. São Francisco: Jossey Bass.

(1985) Organizational culture and leadership: a dynamic view. San Francisco, Jossey Bass.

Schuster, M. E. (2008) Mercado de trabalho de tecnologia da informação: o perfil dos profissionais demandado, 2008. $59 \mathrm{f}$. Trabalho de Conclusão de Curso (Monografia)Instituto de Filosofia e Ciências Humanas, Universidade Federal do Rio Grande do Sul, Porto Alegre.

Silva, F. F. A. e Correia, M. V. A (2013) percepção dos valores organizacionais e sua influência no clima e na satisfação no trabalho em uma instituição de ensino superior privada. Revista Científica Semana Acadêmica, v. 1, n. 7. Fortaleza.

Silva, N. A. (2008) Percepção da cultura organizacional pelo cliente interno: o caso polita - indústria e comércio de pedras polidas LTDA, 2008. 66 f. Trabalho de Conclusão de Curso (Monografia)-Centro de Ciências Humanas, Letras e Artes, Universidade Federal de Viçosa, Viçosa.

Siqueira, D. M., Vieira, A. M. (2012) Valores Organizacionais: percepção e legitimação. Revista Gestão \& Tecnologia, v. 12, n. 2, p. 168-191, jul./nov. Pedro Leopoldo.

Tamayo, A. (1998) Valores Organizacionais: Sua Relação com a Satisfação no Trabalho, Cidadania Organizacional e Comprometimento Afetivo. Revista de Administração, v. 33, n. 3, p. 56-63, jul.set. São Paulo.

Tamayo, A. e Gondim, M. G. C. (1996) Escala de valores organizacionais. Revista de Administração, v. 31, n. 2, p. 62-72, abr./jun. São Paulo.

Tamayo, A., Mendes, A. M. e Paz, M. G. T. DA (2000). Inventário de valores organizacionais. Estudos de Psicologia, v. 5, n. 2, p. 289-315. 
Tavares, F. P. (1996) A cultura organizacional como um instrumento de poder. Caderno de Pesquisas em Administração, v. 1, n. 3, p. 21-22, 2 o Sem.

Vergara, S. C. (2015) Métodos de pesquisa em administração. 6. ed. São Paulo: Atlas.

Vieira, M. S. O. C. e Gomes, D. C. (2013) Valores Organizacionais numa Instituição Pública de Ensino do RN. HOLOS, v. 3, n. 29, p. 77-89.

Zanardi, F. e Silveira, S. R. (2015) Perfil dos Profissionais e das Empresas de Tecnologia da Informação (TI) da Cidade de Frederico Westphalen - RS. 